\title{
Framing intellectual capital for elite athletes
}

\author{
Roberto Aprile \\ Department of Management, University of Bergamo, Bergamo, Italy \\ Mario Nicoliello \\ Economics, University of Genoa, Genoa, Italy, and \\ Susanne Durst
}

Business Administration, Tallinn University of Technology, Tallinn, Estonia and

School of Business, Innovation and Sustainability, Halmstad University, Halmstad, Sweden

\begin{abstract}
Purpose - This conceptual paper proposes an intellectual capital (IC) framework dedicated to elite athletes (EA) to demonstrate the usefulness of IC on individual persons. Thus, it connects EA with the concept of IC. Design/methodology/approach - The paper is inspired by the classical IC dimensions (human capital, structural capital and relational capital), which are used to develop the IC framework for EA. An exemplary case study is used to validate the framework.

Findings - It is argued that there is a need to adapt the traditional IC framework for EA. Therefore, this paper proposes a specific IC framework consisting of natural capital, sports capital and media capital.

Research limitations/implications - This paper deals with EA and the sports industry, but should be extended to other sectors where aspects such as image and celebrity represent significant intangible resources. Practical implications - The proposed IC framework can help EA and their managers to better understand how IC value is created.

Originality/value - This paper extends the IC concept to other fields of application, i.e. EA, and thus individual persons.
\end{abstract}

Keywords Intellectual capital framework, Natural capital, Sports capital, Media capital, Elite athletes, Sport Paper type Conceptual paper

\section{Introduction}

The business of sports has become a big business. Elite athletes (EA in the remainder of the paper) can earn enormous incomes through the practice of their sports, other contracts, and the successful marketing of their image rights and presence in social and mass media. Simultaneously, many of these athletes have become social influencers in fashion, social behaviors and even political viewpoints (Su et al., 2020).

The sports sector, particularly professional sports, has a high level of intangible assets (Wicker et al., 2012); reputation, image, the level of innovation and not to forget the athletes themselves can be mentioned in this context. While in the past these elements resided primarily with the sports companies, they are now also related to EA who have become billionaire celebrities, which in turn made athletes the main assets of sports companies or clubs (Puspitasari et al., 2019).

A study by Pedro et al. (2018) has shown that extant research on intellectual capital (IC) tends to focus on organizations and has only recently been extended to the IC of nations and

(C) Roberto Aprile, Mario Nicoliello and Susanne Durst. Published by Emerald Publishing Limited. This article is published under the Creative Commons Attribution (CC BY 4.0) licence. Anyone may reproduce, distribute, translate and create derivative works of this article (for both commercial and non-commercial purposes), subject to full attribution to the original publication and authors. The full terms of this licence may be seen at http://creativecommons.org/licences/by/4.0/legalcode. 
JIC

23,7

2

regions. The same research also mentions that the sports industry has not yet been an object of analysis, despite its increasing relevance. One of the few examples is the paper by Vitolla et al. (2021) that focuses on IC disclosure practices of top football clubs or the one by Leitão and Baptista (2019) that addresses the IC and brand value of English football clubs.

Similar can be observed at the individual level. The role of IC in conjunction with individual EA is underdeveloped. Extant research has focused on athletes as brands (Arai et al., 2014), and how to manage these brands (Gladden and Funk, 2001; Na et al., 2020). There is also research that addressed athletes for product or brand endorsement (Carrillat et al., 2014), their impact on endorsed brands (Sato et al., 2019) or how accounting is treating them (Puspitasari et al., 2019). Although this appears promising, this research is recent and appears rather fragmented. Hence, it indicates a rather limited focus on IC and thus understanding even if it is well known that EA such as Ronaldo or Hamilton can generate enormous incomes through their contracts or successes in sport and by exploiting their images. This stresses the need for more research to broaden the boundaries of IC research. The present research extends the scope of analysis to EA; an aspect that, to our knowledge, has not been addressed in the extant IC literature yet (relating to IC frameworks in particular). Our study executes a micro level of analysis, i.e. it focuses on the IC found with EA.

We define EA as professional sportsmen and sportswomen who can generate relevant earnings not only by taking advantage of their specific human capital (HC), their specific skills and competencies in their respective sport but even by exploiting additional IC values such as their images.

The overall aim of this paper is to advance current IC research and its areas of application by presenting a conceptual paper that attempts to conceptualize an IC framework applied to EA. To develop this framework, we rely on the three traditional IC components, i.e. HC, SC and relational capital (RC) (Bontis, 1998; Edvinsson and Malone, 1997), and the specific setting found with EA. The framework is the outcome of a theoretical analysis of the suitability of the traditional IC components in the context of EA. Given the specific features of EA that are not found with ordinary athletes, our analysis concludes that it is necessary to propose new components to address this situation. To validate the developed framework Usain Bolt is used as an exemplary case. This is justified by the fact that Bolt is an athlete who has recently ended his career that offers the opportunity to study his entire sporting career.

The remainder of this paper is structured as follows. The next section briefly summarizes existing research on IC frameworks to demonstrate not only the relevance of the present study but also its positioning within existing research. Section 3 discusses the most relevant characteristics of EA and thus sets the frame for the development of a specific IC framework. The sports sector is briefly covered in this section too. Section 4 analyses the suitability of applying the traditional IC framework with EA and, based on that we propose a new IC framework. Section 5 analyses the case study of Bolt to validate the proposed framework, and Section 6 ends with the conclusions.

\section{Theoretical background}

As mentioned, this paper is grounded in the traditional IC components. It follows Guthrie et al. (2012, p. 70) who noted that the commonly accepted terminology of IC which is the outcome of past research activities and that "have contributed to determining an almost universally accepted theoretical framework that divides IC into three elements related to human, structural/ organizational, and relational/social capital dimensions". It is also in line with Warkentin et al. (2021) recent Guest Editorial in this Journal where they wrote that "IC comprises human capital (of employees), organizational (or collective) capital and relationship capital” (p. 433).

While the dimensions may be labeled differently in the existing literature, they refer to $\mathrm{HC}$ (the knowledge embedded in people), SC (the knowledge embedded in organizations and their 
systems) and RC (the knowledge embedded in customers and other relationships external to organizations).

Edvinsson and Malone (1997), for example, proposed a classification split into HC and SC, with the latter further subdivided into organizational capital and customer capital. The SaintOnge Model (1996) consists of HC, including the abilities of the individuals required to provide solutions to customers; SC, including the depth (penetration), width (coverage) and attachment (loyalty) of customers and the profitability they represent; and customer capital which includes an organization's ability to meet market needs.

Based on a systematic review of IC classifications, Aisenberg Ferenhof et al. (2015) proposed an aggregated and consolidated IC meta-model highlighting the main IC dimensions and sub-dimensions. According to the model, the main dimensions are HC, SC, $\mathrm{RC}$ and social capital. As regards the sub-dimensions, $\mathrm{HC}$ seems to cover motivational aspects, interpersonal relationships, knowledge, skills, attitudes and agility. SC is divided into innovation capital, process capital, technological capital and organizational capital, while $\mathrm{RC}$ covers the sub-dimensions of customer capital and business capital. Finally, social capital consists of social actions and interactions. There are also studies (e.g. Mouritsen et al., 2001; Inkinen et al., 2017) that have attempted to further improve the IC classification and components. Using Skandia's IC supplements, Mouritsen et al. (2001) showed the potential power of using IC statements for internal and external communication. Inkinen et al. (2017), by doing an international comparison of IC categorization involving five countries, aimed at showing potential similarities and differences regarding the constitution of relevant IC in firms triggered by country-specific institutional dimensions.

IC frameworks have predominantly been applied to private organizations. As regards the sports sector, football seems to be the sport that has triggered the highest interest, which is not surprising given the popularity of this sport and the corresponding media interest (West, 2016). The IC dimensions utilized also confirm the use of the three traditional IC dimensions. Yet a few exceptions can be found (e.g. Inkinen et al., 2017) which demonstrate that there are cases that require an adjustment of the dimensions to picture the given situation precisely. IC frameworks on individuals are missing, thus underlining the relevant niche this paper wants to fill.

\section{The context: elite athletes}

Before EA are introduced, the sports sector needs to be covered briefly. This sector continues to gain widespread, mass-media diffusion and increasingly requires experts able to combine the traditional "not-for-profit" mission of achieving success with a "for-profit" approach of maximizing economic benefits. Hence, the operation of contemporary sports companies requires the same management principles and practices as traditional companies (Hammerschmidt et al., 2021).

Athletes are the key actors of the sports sector as they are the protagonists of the competitions. When they compete within the boundaries of professional sports at top levels, the best of these athletes can generate enormous incomes and develop their own business model(s) to continuously improve their capitals and manage their overall career.

Time plays an important role in the careers of EA. The time span can be distinguished into three main periods that are (1) pre-career, which describes the period in which generally young athletes are not professionals but amateurs (Sanderson and Siegfried (2015)), (2) professional active period and (3) post-retirement (Martin et al. (2014)).

The focus of our paper is on the professional active period, in particular on the period in which EA develop, by achieving sports success, a brand value and in some cases even become celebrities-athletes (Andrews and Jackson, 2001).

Extant literature appears to have gradually focused on the role of athletes. In past research athletes were mainly considered as "endorsers" of products or services (Ohanian, 1991; 
JIC

23,7

4

Choi and Rifon, 2007), while more recently the emphasis has been put on studying their role in co-branded products (Seno and Lukas, 2007), as autonomous brands (Braunstein and Ross, 2010; Arai et al., 2014) and as pure entrepreneurs (Parris et al., 2014).

Important is also the distinction between "employee athletes" and "free-lance athletes". Athletes playing for teams receive a regular wage from their clubs or associations. This is the case, for example, of not only football but also Formula One and road cycling. Here, the clubs provide for the trainers, therapists and other structural issues relevant to be able to practice the sport. There are also athletes who, without working for a specific team, receive a salary from their country because they represent it in international competitions. The salary allows these athletes to concentrate on their sport (Parris et al., 2014).

Other athletes can be completely freelance, as in the cases of tennis players and golf players. They generally receive money by winning competitions or matches (prize money) and have to pay for entry fees of competitions, travel expenses, equipment, training and maintaining their health.

Relevant additional sources of income are provided by sponsors that can be divided into technical sponsors (sponsors related to equipment) and other sponsors. Sponsors can offer yearly or multi-year contracts that can represent, if the athletes are famous, important sources of money and even exceed the salaries or prize money (Szymanski, 2003).

Further sources of revenues can be generated by exploiting their image. This can happen in different ways, by using social media, advertising, publishing books, playing in movies, making conferences or doing other activities. EA can also receive money by just participating in sports meetings or television programs.

The role of managers and agents is relevant too (Burke, 1993; Hancock et al., 2010). The latter, e.g. in football, signs the agreements with the football clubs. Agents can also represent the athletes by signing contracts with sponsors and other institutions, and contribute to the personal growth of the athletes and their professional career. Managers are more focused on only one athlete and follow him/her during each phase of the professional career and in many cases even non-professional life (e.g. Ricky Simms, the manager of Bolt).

Further people include attorneys, accountants, tax consultants, insurance consultants (Burke, 1993) as well as mental coaches, communications experts and public relations officers who are involved in commercial undertakings and branding (Braunstein and Ross, 2010; Arai et al., 2014). Finally, coaches and trainers are involved to work on the athletes' competitive performance (Hansen, 2015).

The analysis of the lives of EA clarifies that training is one of the most important activities, which also takes up a lot of time in their lives.

Training activity generally absorbs more than half of the year and can spread to as much as 11 months depending on the sport. Training is essential if athletes want to perform at elite levels (Hansen, 2015). Coaches generally determine the training schedules, and it is possible to divide training into two phases: the gym and the field (the track, the pool, the pitch, etc., depending on the discipline). Outside the competition period, the gym phase prevails while during the competitive season training mostly takes place in the field.

Competitions are the crucial moments when athletes have to capitalize on their training and can show whether the hard training has paid off.

Competition schedules differ depending on the sport, affecting the distribution of the time devoted to this activity. Some sports are characterized by seasonality, such as Alpine and Nordic skiing, while others are spread across more of the year. Another aspect is related to the quantity of competitions athletes have to play during the year. The competitions can also vary in terms of their relevance; league playoffs are more important than regular season games, and world championships like football's World Cup are more important than national competitions. 
All these aspects impact the training activity, its intensity in particular, as athletes should try to achieve the best results in the most important sporting events. On the contrary, in sports such as Formula One and MotoGP, all competitive events theoretically hold the same importance as each event contributes the same total points to the final classification.

In some specific sports (e.g. football and basketball), athletes can play both on their country's national teams and their league teams which, conversely, results in a longer competition phase. This extended phase is significant for both economic reasons and "sentimental" reasons. Limiting our analysis to economic reasons, being selected to a national team generally increases both the value and the wages of the athletes concerned.

Institutional activities refer to the time that athletes spend on managing business affairs such as contractual relationships with the club, sponsorship agreements and image rights. The institutional activities concern all professional athletes. The core of these activities is the relationship with sponsors, who represent one of the most important business levers for athletes (Parris et al., 2014). Institutional activities absorb time too and can be done in favor of the athletes' team or for themselves.

In team sports, EA are expected to perform certain activities, usually, press conferences, appearances and public relations events for the team, to fulfil the agreements with their clubs. The most famous and well-paid athletes hire agents and staff to help them manage these kinds of activities since more of their time is taken up by institutional activities compared with lesser-known athletes.

Athletes also run other activities that absorb time outside of competition. They can be related to public relations, television appearances, interviews, participation in social events, book publishing, etc. These activities make possible additional revenues for athletes. The time devoted (and available) to these other activities depends on the sport. If the sport is very popular, the possibility of being involved in extra activities is higher than in a sport with low popular appeal.

Finally, the time left is devoted to leisure and private life and is influenced by the activities mentioned before. Athletes can use this leisure time to improve their media exposure and increase the market value of their images as well, e.g., by uploading holiday photos on their social media sites.

Based on the above-presented, athletes' seasons can be divided into five phases, regardless of the sport in which they are involved: (1) training activities, (2) competitions, (3) institutional activities, (4) other activities, and (5) leisure and private life.

In this paper, EA are equated with companies that aim at maximizing earnings and sporting successes. For athletes in team sports, part of these entrepreneurial activities is taken over directly by the club, whereas in individual sports, athletes do have more freedom and can choose the people "around them" that become members of their staff, which is comparable with the hiring process found in traditional companies. This is the case of the Italian swimmer Federica Pellegrini, who can choose her coach. In sum, the issues discussed above allow us to understand the similarities between traditional companies and EA.

\section{Proposal of conceptual IC framework}

In this section, we analyze if the traditional IC dimensions are consistent with EA (section 4.1) and then based on the findings propose a new conceptual model (section 4.2).

\subsection{The traditional IC dimensions and elite athletes}

The traditional IC dimensions are the starting point to check their suitability for EA. Warkentin et al. (2021, p. 433) specify that "research within the domain of IC can be conducted at the individual (micro) level, the group (meso) level, and the organizational (macro) level, and is even the focus of industry level and country-level research". 
JIC

23,7

6

4.1.1 Human capital. Baima et al. (2021) and Hormiga et al. (2011) put in evidence the pivotal role of $\mathrm{HC}$ in the value creation process. Martin et al. (2013) explain that subjects with greater and better skills can generate better performance, benefiting from ideas, experiences and motivations. Aisenberg Ferenhof et al. (2015) recall the work of Schultz (1961) that can be considered a precursor of $\mathrm{HC}$ since both knowledge and skills are viewed as forms of capital. $\mathrm{HC}$ is defined as a set of knowledge, skills and abilities that reside in the individual and that are used by him/her. Transferred to the athletes' world, many of these features are incorporated into a single athlete. Becker (1964) stressed the importance of education, medical care and moral values, since these features increase gains, income and improve health. Yusoff et al. (2004) draw attention to the fact that it is not enough to only have knowledge and skills, but there is a need to put them into practice. This aspect is important to distinguish between pure talent and to the ability to put them also into successful sports results. Formal education, continued training and experience combined with the successful use of talent are necessary to enforce the athlete's $\mathrm{HC}$ to achieve the sporting objectives. The coaches are there to support the athletes in each phase of their professional development (Hansen, 2015).

Knowledge, competence, skills, the experiences of employees and training networks form a complex system (Andersen et al., 2015) generally involving people within the company to allow the organization to achieve its aims. A common element between athletes and traditionally defined companies is represented by their respective employees and collaborators. Since athletes can be (and are) supported by an increasing number of people with different skills and specializations, such as agents, trainers, nutritionists, psychologists and even technical analysts who compare the performance of athletes and their rivals, the athletes' world has become more consistent with traditional companies. In particular, "organizational support is usually the highest when athletes are at the peak of their career" (Stambulova et al., 2011, p. 399). This already shows the link to the other two IC dimensions to be discussed below.

Skills, abilities, experiences and training, however, are not ancillary features but rather represent the basic elements surrounding performance.

4.1.2 Structural capital (SC). Traditional companies invest money to develop their organizations continuously. Innovation plays an important role in this regard and part of these activities could comprise the filing or buying of patents or other intellectual properties. The big companies, in particular, create internal R\&D departments and implement clear procedures to register and manage their intellectual properties (Woolcock and Narayan, 2000).

Organizations depending on their size and industry can use a variety of intellectual property (IP) to benefit from what they invented or created. The possibilities of EA vary in this respect. Patents, for example, are of little importance as athletes generally neither apply for nor acquire them. Trademarks are somewhat different in this context because names and images can be registered and protected. Distinctive gestures such as Bolt's archer's pose cannot be registered and therefore cannot be subject to copyright even if it helps generate a type of brand association (Gladden and Funk, 2001).

Organizational processes, procedures and databases assume a different role with athletes than with companies. For athletes, such elements are more concentrated and less dispersed, referring to the number of people involved and the geographic dispersion. Databases were not used by athletes till recent years, but the professionalization of sport and the availability of new digital solutions have incentivized the use of data to improve the performance of athletes.

4.1.3 Relational capital. Regarding $\mathrm{RC}$, it is useful to recall the distinction between "employee athletes", and "free-lance athletes". For the former, it is important to have access to relations with teams that increases the possibility to achieve sports success and as a consequence to receive hefty salaries. Given the role of agents, such RC is developed and maintained by these persons and not the individual athlete (Burke, 1993; Hancock et al., 2010). 
In this case, EA can develop and further their $\mathrm{RC}$, not by their direct efforts, but primarily by carefully selecting a good agent. Thus, the athletes benefit from the $\mathrm{RC}$ of their agents.

Other important relations should be created and maintained with fans and supporters (Da Silva and Las Casas, 2017). This is important for employee athletes but even more for freelance athletes since in many cases, the latter can generate much more income from sponsors and sometimes from the use of social networks, compared to the revenues that derive directly from the sports activities (e.g. the case of Bolt).

A further important aspect of $\mathrm{RC}$ is represented by the relationships with customers and partners. While in general there is no direct relationship between athletes and clients in the traditional meaning, these relationships are significant elements that should be adapted to the context of athletes.

RC is positively affected by sports success. Leitão and Baptista (2019) confirm this positive relationship. For Arigil and Pennazio (2011), without victories, any club will find it difficult to attain commercial success. Reputation most lends itself to sports. Reputation can assume both positive and negative dimensions. If athletes perform charitable activities or take part in community events, their reputational values grow. Conversely, if athletes are involved in doping or other scandals, their reputational values collapse (Glantz, 2010).

Social networks play a crucial role in the reputation of athletes and on their revenues (Lou and Yuan, 2019). Therefore, the continued management of these networks has become a critical business lever for athletes. Even when moving to new teams, athletes can lose or acquire fans, both because they can generate a sort of co-branding with their teams (Seno and Lukas, 2007), and due to their perceived ethical or unethical behavior (e.g. moving to the rival team, or moving just for money without gratitude with the team that grew up the athlete making him/her famous).

Having good relationships in team sports generally increases the value of the athletes and the teams. Relationships are more complicated when competitions are among teammates (generally in motorsports) as they are based on an uncommon mix of cooperation and competition. Rivalries among teammates can increase the popularity of the athletes involved. Finally, there are the relationships between athletes and business partners, i.e. people who exploit the value of an athlete's public image or name, transforming it into a brand (Braunstein and Ross, 2010; Arai et al., 2014; Ratten, 2015).

In summary, it can be said that the traditional IC framework has many aspects that can be applied to EA. However, there are also a large number of athlete-specific characteristics that make it necessary to adapt the framework/its traditional dimensions.

\subsection{Development of IC framework for elite athletes}

Moving to the individual level the traditional IC classification only partially fits for them since they are not completely assimilable to traditional companies. In this section, we propose our own model that adapts the traditional classification in a more coherent way for EA.

$\mathrm{HC}$ can be related directly to the athletes' characteristics or even to their supporting staff. This is not the same for companies, whose $\mathrm{HC}$ is made only by their managers, employees and collaborators. This difference suggests the opportunity to create a specific classification referring to the characteristics of the athletes. It can be called natural capital $(\mathrm{NaC})$ since many of the main conditions for success are represented by pre-conditions (e.g. talent and physical characteristics) that can be developed over years.

Since the natural goal of EA is to achieve sports success, and they behave and organize their life to achieve this result, sports capital $(\mathrm{SpC})$ represents a specific fundamental category that has no corresponding aspects in traditional companies. Since to achieve these results, athletes are not alone but cooperate with other people, some elements of $\mathrm{HC}$ and SC can be included in this category.

\section{Elite athletes}


JIC

23,7

8

Since EA directly expose themselves, their name, their face, and in many cases, their private life, they are subject to an immense media exposure, which we identify as a third IC capital that we name as media capital $(\mathrm{MeC})$. It has many similarities, as we will analyze afterward, with the last element of the traditional threefold IC classification, represented by RC.

Based on the previous analysis, we propose to adapt the concept of IC into three fundamental dimensions to make it fit for EA:

(1) $\mathrm{NaC}$

(2) $\mathrm{SpC}$

(3) $\mathrm{MeC}$

We summarize these dimensions as follows. NaC means "to be" or "to be able" (i.e. athletes are and athletes can do), $\mathrm{SpC}$ means "to win" (athletes win), $\mathrm{MeC}$ means "to appear" and to communicate (athletes appear and try to be impressive for the audience). In this conceptual paper, $\mathrm{SpC}$ ranks between $\mathrm{NaC}$ and $\mathrm{MeC}$. While $\mathrm{NaC}$ and $\mathrm{MeC}$ could be applied to other sectors too, $\mathrm{SpC}$ is specific to the sports sector and is viewed as a "characterising capital".

4.2.1 Natural capital. $\mathrm{NaC}$ can be described as an athlete's natural characteristics. This capital can lead to a win and to have superior performance on the field and fame off the field. In the proposed model, $\mathrm{NaC}$ is primarily affected by technical skills and aesthetic qualities. Both elements represent natural gifts that athletes must improve through training activities to reach an elite level they can be distinguished in "innate part of the talent" and "acquired part" (Stambulova et al., 2011). NaC, therefore, represents a precondition for the development of the other two capitals.

Technical skills and sporting talent (Hoffmann and Wulff, 2015) can be seen in the actions of athletes in their disciplines, combining their natural endowments with technical training levels (e.g. the double pass for Ronaldo). The more graceful the movement, the more fans are enchanted, increasing the value of the athlete's image since such activities can stimulate emotional responses and reactions in consumers (Arai et al., 2014). The authors specify (p. 101) that "if the athlete has a clear and unique playing style that fans can easily identify with, strong identification will likely develop and lead to loyalty".

Natural abilities and training regimes have to be carefully managed to find the right equilibrium to avoid injuries and to establish schedules that will allow athletes to reach peak performance at the most relevant competitions.

In general, experience is an important factor that allows athletes to find the proper combination of training and natural skills to maximize performance.

It can happen that to improve their $\mathrm{NaC}$ and consequently $\mathrm{SpC}$, athletes make use of doping that positively affects their $\mathrm{NaC}$, as it can improve - albeit artificially - their performance. This, however, is a double-edged sword, since it can lead to a significant loss of reputation when discovered (Pöppel et al., 2021).

Even aesthetic qualities are a natural gift. A more photogenic athlete has a greater image value and therefore more $\mathrm{NaC}$. Sharapova is an example of an athlete whose aesthetic qualities add value to the technical skills.

While technical skills are primarily reflected in sports results, measurable first by the number and relevance of victories and second in advertising possibilities resulting from the wins, aesthetic qualities mainly affect media success and other forms of revenue.

4.2.2 Sports capital. The second element of this model and probably the most complex is $\mathrm{SpC}$, which can be measured from two perspectives: sporting success and economic rewards. There is thus a relationship between these two aspects. In the athletes' business model, sporting success leads to economic success. 
$\mathrm{SpC}$ is a form of $\mathrm{HC}$ and $\mathrm{SC}$ that finds concrete expression in sports and economic results. Measuring this capital depends on the sport practiced. It can be measured by the number of wins, the relevance of the wins (e.g. Olympics), the records set, and if the wins come in individual games or season-long competitions. The more the athletes win on the field, the more the value of their capital increases. Arai et al. (2014, p. 101), based on Richelieu and Pons (2006), specify that winning does not have to be a constant success but can be the extraordinary records that define the athletes' brands as competitive.

The elements affecting this capital are, above all, the technical staff and the management of the athletes' time.

Good sports results are based on elements such as the choice of the competitions (preferred to compete in high-profile events while Gatlin, his main rival, generally participated in almost all meetings), the right coach (Italian swimmer Federica Pellegrini missed out on an Olympic medal in 2012 mainly because her relationship with her coach had been catastrophic), the training location, and the right balance between training and rest. Other aspects affecting $\mathrm{SpC}$ are the training methodology, the relationships with teammates, the choice of team, and the athletes' lifestyle.

Concerning doping, some athletes use banned substances to improve their $\mathrm{NaC}$ but with the main aim to enhance their $\mathrm{SpC}$. Therefore, doping is considered a shortcut to achieve sports success. However, when an athlete tests positive for a prohibited substance, the doping generates negative impacts. In particular, regarding $\mathrm{SpC}$, the related fines generally include disqualifications, exclusions from competitions and eventual revocation of previous results (as in the case of the cyclist Armstrong).

4.2.3 Media capital. The goal of $\mathrm{MeC}$ is to increase the reputation of athletes regardless of their victories. We do not use the terms $\mathrm{RC}$ because for athletes it lacks a direct relationship with the customers, but the relationship is generally and prevalently indirect. The mediatic world has a connection with social media (Lardo et al., 2017), but it is much more general to cover different forms of media.

The conceptual model of athlete brand image proposed by Arai et al. (2014) considers three key dimensions: athletic performance, attractive appearance and marketable lifestyle. This opens the analysis to both on-field characteristics and performance and off-field aspects, mainly related to the marketable lifestyle. Physical structure and connected physical attractiveness can represent an element able to affect both on-field and off-field "performance".

At the core of $\mathrm{MeC}$, in addition to sports results, there is the reaction to athletes' personalities and popularity.

$\mathrm{MeC}$ is affected by athletes' appearances on television, in newspapers and on social networks, even if all these aspects are generally not managed in a professional way. To earn $\mathrm{MeC}$, athletes must differentiate themselves in the global sporting arena (Ratten, 2015). There are different ways to achieve this result, i.e. being sympathetic (e.g. Bolt), having empathy with the public (the smile of Lindsey Vonn being attractive) or having an unusual look (the half beard of Italian high jumper Tamberi before the Olympics Games 2020). Also having good relations with journalists, and effectively managing social networks (e.g. Ronaldo with more than 300 million followers) can increase MeC.

Even love affairs and breakups, in particular with other celebrities, can increase $\mathrm{MeC}$ due to the increased media attention. Sentimental relationships involving famous athletes always fill the pages of gossip magazines, flood websites and arouse the curiosity and interest of large audiences (e.g. Vonn and Tiger Woods when they were romantically linked).

$\mathrm{MeC}$ is also affected by athletes' charisma. This skill can help an athlete to transcend the sports sector. For example, Muhammad Ali's MeC, with his civil commitments and battles for human rights, surpassed his sports accomplishments. 
JIC

23,7

In summary, $\mathrm{MeC}$ results in an increase in athletes' revenues by leveraging public relations, sympathy, empathy, looks, relationships with journalists, the use of social media, romantic relationships, sponsors, lifestyles and team selection. It is generally related to results in competitions, institutional activities, other activities and the use of leisure time.

Returning to doping, this phenomenon negatively affects $\mathrm{MeC}$ as it represents a stain on an athlete's career, and it generally results in suspension of sponsorship agreements, reducing the possibility of exploiting the athlete's image and leading to fines, suspensions or expulsions by the sport's governing body.

Table 1 summarizes the components, showing the aspects of each form of IC.

To further develop the framework and also considering the specific situation found with $\mathrm{EA}$, in particular, the three additional dimensions are also linked with the five phases describing athletes' season as outlined before.

Training activities affect $\mathrm{NaC}$, allowing athletes to become stronger and more skilled. Training is the heart of the athletes' season and as a result, the crucial phase that affects the formation of capital (Côté and Fraser-Thomas, 2007).

Competitions have an impact on $\mathrm{SpC}$ and $\mathrm{MeC}$ because victories or defeats define the success of athletes $(\mathrm{SpC})$ and victories increase visibility and fan following $(\mathrm{MeC})$.

Institutional activities and other activities impact $\mathrm{MeC}$ as relations with sponsors and public appearances as well as the press and media campaigns can increase athletes' fame and notoriety and consequently the number of followers on social networks. Ohanian (1991) talks about the "credibility model", which estimates that the brand has a higher value when athletes have active participation and give a positive contribution to society, and they exhibit virtuous behavior.

Finally, leisure and private life affect all three forms of capital. How the spare time is used can increase or decrease the different forms of capital and it is relevant to an athlete's business model. This finds confirmation in the study of Choi and Rifon (2007), in which it's stated that celebrities achieve their status not only because of their outstanding on-field performance but also in their distinct lifestyle, and in other public relations researches that have investigated also the off-field dimension (Andrews and Jackson, 2001).

As we can see, the three additional IC dimensions are connected. For example, $\mathrm{NaC}$ affects the other two because health and talent are the basis of victories while looks are one of the bases of media success. $\mathrm{SpC}$ impacts $\mathrm{MeC}$ because the more the athletes win, the more famous they become.

\section{The case of Bolt}

To validate the suitability of the above-proposed framework, we tested it using Bolt as an illustrative case, since this case allows us to adopt "a whole career" approach considering all his athletic lifespan. Bolt is one of the most famous EA in the world who retired from sprinting in 2017 after the World Championships in London. Bolt was chosen because he developed over years a relevant IC value and his retirement allow for an examination of how he improved, increased and exploited his IC throughout his career. To reconstruct his career, we drew information from Bolt's website: usainbolt.com. We retrieved additional information from other websites, the financial journal Forbes and athletic information from the books by Matthews that list relevant data related to athletic events.

\subsection{Natural capital}

The first words of Bolt's biography on usainbolt.com are emblematic: "the most naturally gifted athlete the world has ever seen”. Bolt's NaC lies in his natural abilities. Though he was considered to be too tall for a prototypical sprinter, he has honed a perfect style through 


\begin{tabular}{|c|c|c|c|}
\hline Natural capital & Sports capital & Media capital & \\
\hline $\begin{array}{l}\text { Natural aspects } \\
\text { - } \quad \text { Native characteristics } \\
\text { - } \quad \text { Mental strength/ } \\
\\
\text { - } \quad \text { fragility } \\
\text { - Talent } \\
\text { - } \quad \text { Technical skills } \\
\text { Improving elements } \\
\text { - } \quad \text { Training activities } \\
\text { - } \quad \text { Experience }\end{array}$ & $\begin{array}{ll}\text { Professional choices }(P C) \\
レ & \text { Technical choices } \\
\text { Other aspects } \\
\text { Results } \\
\text { - } \quad \text { Competitions' choice } \\
\text { - } \quad \text { Technical staff } \\
\text { - } \quad \text { Trofessional management } \\
\text { - } \quad \text { Coach } \\
\text { - } & \text { Team selection } \\
\text { - } & \text { Place of training } \\
\text { - } & \text { Rest period } \\
\text { - } & \text { Lifestyle } \\
\text { - } & \text { Relationships with } \\
& \text { teammates } \\
\text { - } & \text { Wins } \\
\text { - } & \text { Sport success }\end{array}$ & $\begin{array}{ll}\text { } & \text { Natural aspects } \\
レ & \text { Professional choices } \\
\text { Other Aspects } \\
\text { - } & \text { Reputation } \\
\text { - } & \text { Public relations } \\
\text { - } & \text { Sponsor } \\
\text { - } & \text { Relationships with } \\
& \text { journalists } \\
\text { - } & \text { Social media } \\
\text { - } & \text { Media exposition } \\
\text { - } & \text { Popularity } \\
\text { - } & \text { Sympathetic } \\
\text { - } & \text { Empathy } \\
\text { - } & \text { Charisma } \\
\text { - } & \text { Looks } \\
\text { - } & \text { Gossip }\end{array}$ & $\begin{array}{r}\text { Table } 1 . \\
\text { Components of IC } \\
\text { framework for EA }\end{array}$ \\
\hline
\end{tabular}

training and sacrifices. Jamaica, known as the land of the sprinters because it has produced several world-class competitors in the field, is where Bolt's NaC began. In Table 2, the elements making up Bolt's $\mathrm{NaC}$ are broken down.

\subsection{Sports capital}

"As early as age 14, young Usain was opening eyes with his lightning speed from regional championships in western Jamaica. He announced his arrival to the wider global audience in July 2002 when at the IAAF World Junior T\&F Championships, he won the individual gold medal, winning the $200 \mathrm{~m}$ in $20.61 \mathrm{~s}$ " (usainbolt.com).

Having abundant $\mathrm{NaC}$ made it easier to graft on the $\mathrm{SpC}$ that has few equals among athletes. Bolt's strategy of avoiding lesser meetings to concentrate on the most significant events meant his victories were few but of the highest-profile.

Bolt's first major international win came when he was 16 years old with a gold medal at the World Junior Championships in Kingston, Jamaica, in 2002 (Matthews, 2003). At the time, Bolt was still relatively unknown as he concentrated on training and avoided low-profile events, meaning his victories in the early years were few. We can, therefore, split Bolt's career into three periods.

\subsection{First period (2003-2007)}

From 2003 to 2007, Bolt did not win major international events, but he had to face some injuries, he had to gradually enter the logic of professionalism. And above all, he made the decision that changed his life: to run not only the $200 \mathrm{~m}$ but also the $100 \mathrm{~m}$.

\begin{tabular}{|c|c|}
\hline Natural capital & Bolt \\
\hline $\begin{array}{l}\text { Native } \\
\text { characteristics }\end{array}$ & Jamaica is known as the land of sprinters and has produced several world-class athletes \\
\hline Mental strength & Focused on his aims with little recreation during the season \\
\hline Talent & Impressive running speed \\
\hline Technical skills & Improved his start from the blocks at the beginning of a race with dedicated training \\
\hline Aesthetic qualities & His stride and speed intimidated competitors \\
\hline Training activities & Trained in all facets of the sprint \\
\hline Experience & $\begin{array}{l}\text { His running and stride improved year to year and allowed him to overcome slow starts } \\
\text { out of the blocks }\end{array}$ \\
\hline
\end{tabular}

Table 2.

Elements of Bolt's $\mathrm{NaC}$ 
JIC
23,7

\subsection{Second period (2008-2009)}

From 2008 to 2009, Bolt won the first of his Olympic golds in the 100 and $200 \mathrm{~m}$ races and set world records. 2008 and 2009 were the magical years of his career, the ones where he hit the peak of speed, realizing chronometric performances that he has never touched up. In these two years, his opponent has been the chronometer, marking times that are still unbeaten today.

5.5 Third period (2010-2017)

From 2010 to 2017, Bolt remained the dominant sprinter and balanced the management of his life. $\mathrm{SpC}$ is relevant in all of these three phases, during which Bolt made fundamental choices as summarized in the subsection "Business model".

\subsection{Media capital}

Usain has been awarded the Laureus World Sportsman of the Year on four occasions; the IAAF Male Athlete of the Year six times as well as many awards in many countries of the world. He has a clothing line with Puma; a range of signature watches with Hublot; a restaurant chain called "Tracks and Records"; an Urban Mobility company "BOLT", a shaving company Champion Shave, an insole company Enertor; the "Usain Bolt Foundation", and he is an ambassador for some of the top brands in the world (usainbolt.com).

Bolt's presence added luster and appeal to track and field competitions and captivated worldwide audiences. Before competitions, he tended to interact with his audience through photos and messages on social media. After his victories, he posed in his signature archer's stance, signed autographs, took pictures with fans, and was gracious in the locker room and press conferences with photographers and journalists.

Bolt's staff built a media personality that has few equals. He has been sought after by a multitude of sponsors but has signed only a few lucrative contracts. His Twitter profile is daily updated with new images.

\subsection{IC evolution}

Bolt's IC evolved over time. In particular, three phases can be underlined, consistent with his career path.

(1) 2003-2007 was the $\mathrm{NaC}$ period that involved rigorous training and many competitive races.

(2) 2008-2009 was the $\mathrm{SpC}$ period when he burst onto the world stage with victories in the Olympics and world championships and set world records.

(3) 2010-2017 was the $\mathrm{MeC}$ period when he managed his athletic career and his global popularity.

The most important factor in Bolt's IC model was the decision to run in $100 \mathrm{~m}$ races in 2008 rather than only in the $200 \mathrm{~m}$ as he had done in previous years. The $100 \mathrm{~m}$ race is the premier event in track and field competitions and the Olympics and the winner is often dubbed the world's fastest man (Matthews, 2009).

Bolt's differing time management is apparent during all three phases.

(1) In the First period, training was the most important activity and this is consistent with the analysis of Stambulova et al. (2011) about the career development of athletes.

(2) In the Second period, competitions became the primary concern because winning and set new records was necessary to establish his reputation and career.

(3) In the Third period, institutional and other activities reigned supreme because managing his popularity became the most important consideration. 
Bolt was able to turn his $\mathrm{MeC}$ into a dollar mine. His earnings have increased exponentially from year to year. Based on a survey carried out annually by Forbes (forbes.com), it is possible to note that in 2009 Bolt's earnings amounted to 3 million dollars, while in 2017 the amount reached 34.2 million.

Bolt's main ability has been to attract business partners and tie them to his figure as a winning man. The first contract was signed in 2002 with the German sportswear company Puma. A bond that is still in place today. To testify to the biunivocal relation of the two subjects, just think that Puma's slogan over the years has become "Forever Faster", the same as Bolt's at the beginning of his career (Ukfashion.com).

The second logo that joined Bolt in 2007 was that of Digicel, a Caribbean mobile phone network (Forbes.com). These agreements confirm that in the first phase of his career Bolt was essentially an athlete (hence the link with Puma who supplies him with the sports material) known at home (Digicel was interested in the Jamaican market).

After the explosion of 2008, the first global brands arrived in 2009. Bolt has tied up with four trading partners: Gatorade, Hubolt, Visa and Virgin Media (Forbes.com). Here we can see the character's ability to advertise products external to the world of athletics but which are reflected in his characteristics.

In 2012, the commercial basket is enriched with three other brands: Celcom, Optus (telecommunications) and Regupol (manufacturer). Finally, in 2016, two Japanese logos arrive All Nippon Airways and Nissan (Forbes.com).

On an economic level, the main partner has always been Puma, which in 2015 extended the sponsorship agreement until 2025, paying Bolt 10 million dollars a year. The other nine sponsors paid Bolt between 1 and 4 million a year. It is therefore understandable that the proceeds from the sponsors are equal to $95 \%$ of the annual proceeds of Bolt, which collects only $5 \%$ from the prizes and engagements of the organizers.

Despite being an athlete, Bolt has earned much more from the surrounding voices, outside the sports world. A gold medal at the World Athletics Championships is worth 60 thousand dollars (Worldathletics.org), so in his career Bolt has brought home from the world championships 660 thousand dollars. In the Diamond League - the one-day meeting circuit the victory was worth 10 thousand dollars, while the total annual compensation received by organizers was around 400 thousand. So, in ten years of a high-level career, the Diamond League has brought Bolt 230,000 in prizes and 4 million in compensation from the organizers.

Despite being a military athlete, that is, belonging to a public sports group, the Jamaican state did not pay Bolt a salary.

The most striking fact is that despite having retired in 2017, Bolt continues to be full of commercial contracts today. The logos of his partners are still present on his website. This affection is explained simply by observing the growth of his followers on social media. On Instagram, Bolt had 1 million followers in 2015, then increased to 3 million in 2016, 6 million in 2017 and 10.6 million today. On Facebook, his page had 500,000 followers in 2010, 750,000 in 2012, 1.2 million in 2014, 1.7 million in 2016, 19.6 million in 2017 and 21 million today. His Twitter profile was followed by 850,000 people in 2011, 1.4 million in 2013, 2.1 million in 2015, 3.5 million in 2017 and 4.8 million today.

Since he is no longer competing, Bolt has become a much more media personality than he was as an athlete. Bolt managed to hit the bull's-eye, changing the nature of his character. When he competed, he was shy and reserved, he did not want to let anyone know about his private life. Today all his releases become public and are documented on social networks step by step. Furthermore, even the photos of his family are no longer confidential but conveyed without any restraint.

We can derive that Bolt's different ICs were developed in a way consisting in focusing on one aspect as a basis on which to develop the others, in a rigorously specific order. 
$\mathrm{JIC}$
23,7

\section{Conclusions}

Extant IC frameworks have mainly been used to evaluate, manage and eventually report on the IC of organizations. Only recently researchers have also added new perspectives or functional dimensions to make the IC framework more applicable to other areas (e.g. Inkinen et al., 2017; Leitão and Baptista, 2019).

This paper follows this recent development and aims to extend the application of the IC framework to individuals, i.e. EA. By focusing on EA, a new sector is also added, i.e. the sports sector, which has been investigated only recently as well (e.g. Vitolla et al., 2021; Hammerschmidt et al., 2021).

More precisely the paper proposes an IC Framework dedicated to EA consisting of $\mathrm{NaC}$, $\mathrm{SpC}$ and $\mathrm{MeC}$. Even though our analysis revealed that there are elements in the traditional IC classification model that apply to EA as well, we also found a need to adapt this framework to the specific characteristics of these intangible-based individuals. This refers, in particular, to the aim to manage the athletes' IC profitably, considering the limited time that the career of a top athlete lasts.

The proposed IC model has been tested on the whole career of Bolt, who has recently retired from competitions but whose $\mathrm{MeC}$ is still enduring. The analysis demonstrates that he developed one IC dimension at a time, based on the different periods of his career. This finding can be viewed as crucial to understand, analyze and eventually manage the career of other EA from an IC perspective.

The three proposed IC dimensions appear to represent specific IC areas in which EA should invest in particular to maximize their sporting and non-sporting activities depending on where they are in their careers.

As the framework takes into consideration the issue of time, a critical factor in the lives of $\mathrm{EA}$, it has a dynamic nature too. The developed framework can also serve as a career planning tool for developing and managing the careers of EA in different sports. Understanding the role of different types of IC dimensions during the career is not only relevant for the individual athletes but also their management improving professional sports management. Using the framework could also be beneficial for sports politics as it can contribute not only to achieving the objectives of the sport at the national level but also to introducing more specific sports measures based on IC.

Given the paper's conceptual nature there are certain limitations which in turn opens several future research avenues. There is a need for further testing and developing the framework by considering both EA that have recently completed their careers and athletes that are still active in competitions to demonstrate the robustness of the framework and its components. Given the framework's focus on individuals and more precisely high professionals, it could be tested and also further developed in other sectors such as entertainment and fashion, which are "celebrity based" and also contain individuals sharing similar factors as EA. Furthermore, future research could also place a particular focus on SpC that is a specific IC dimension, develop it further and compare it across different industries based on celebrities (e.g. fashion stars, movie stars, influencers and retired politicians). Another useful aspect for future research could be to develop specific metrics that could be used to measure each capital dimension of the framework proposed in this paper.

Overall, the proposed framework seems promising for opening up new fields of research relating to the advancement of the field of IC.

\section{References}

Aisenberg Ferenhof, A., Durst, S., Zaniboni Bialecki, M. and Selig, P.M. (2015), "Intellectual capital dimensions: state of the art in 2014", Journal of Intellectual Capital, Vol. 16 No. 1, pp. 58-100, doi: 10.1108/JIC-02-2014-0021. 
Andersen, S.S., Houlihan, B. and Ronglan, L.T. (2015), Managing Elite Sport Systems. Research and Practice, Routledge, London and New York.

Andrews, D.L. and Jackson, S.J. (2001), "Introduction: sport celebrities, public culture, and private experience", in Andrews, D.L. and Jackson, S.J. (Eds), Sport Stars: The Cultural Politics of Sporting Celebrity, Routledge, London, pp. 1-19.

Arai, A., Yong, J.K. and Ross, S. (2014), "Branding athletes: exploration and conceptualization of athlete brand image”, Sport Management Review, Vol. 17 No. 2, pp. 97-106, doi: 10.1016/j.smr.2013.04.003.

Arigil, C. and Pennazio, V. (2011), "Brand equity in team sports: the FC København case study", Master Thesis, Department of Marketing, Copenhagen Business School.

Baima, G., Forliano, C., Santoro, G. and Vrontis, D. (2021), "Intellectual capital and business model: a systematic literature review to explore their linkages", Journal of Intellectual Capital, Vol. 22 No. 3, pp. 653-679, doi: 10.1108/JIC-02-2020-0055.

Becker, G.S. (1964), Human Capital: A Theoretical and Empirical Analysis, with Special Reference to Education, The University of Chicago Press, Chicago.

Bontis, N. (1998), "Intellectual capital: an exploratory study that develops measures and models", Management Decision, Vol. 36 No. 2, pp. 63-76, doi: 10.1108/00251749810204142.

Braunstein, J.R. and Ross, S.D. (2010), "Brand personality in sport: dimension analysis and general scale development”, Sport Marketing Quarterly, Vol. 19 No. 1, pp. 8-16.

Burke, B. (1993), "Negotiations involving agents and general managers in the NHL", Marquette Sports Law Review, Vol. 4 No. 1, pp. 35-50.

Carrillat, F.A., d'Astous, A. and Christianis, H. (2014), "Guilty by association: the perils of celebrity endorsement for endorsed brands and their direct competitors", Psychology and Marketing, Vol. 31 No. 11, pp. 1024-1039, doi: 10.1002/mar.20750.

Choi, S.M. and Rifon, N.J. (2007), "Who is the celebrity in advertising? Understanding dimensions of celebrity images", The Journal of Popular Culture, Vol. 40 No. 2, pp. 304-324, doi: 10.1111/j.15405931.2007.00380.x.

Côté, J. and Fraser-Thomas, J. (2007), "Play, practice, and athlete development”, in Farrow, D., Baker, J. and MacMahon, C. (Eds), Developing Sport Expertise: Researchers and Coaches Put Theory into Practice, Routledge London, pp. 17-28, doi: 10.4324/9780203934937.

Da Silva, E.C. and Las Casas, A.L. (2017), "Sport fans as consumers: an approach to sport marketing", British Journal of Marketing Studies, Vol. 5 No. 4, pp. 36-48.

Edvinsson, L. and Malone, M. (1997), Intellectual Capital: Realising Your Company's True Value by Finding its Hidden Brainpower, HarperCollins, New York, NY.

Gladden, J.M. and Funk, D.C. (2001), "Understanding brand loyalty in professional sport: examining the link between brand associations and brand loyalty", International Journal of Sports Marketing and Sponsorship, Vol. 3 No. 1, pp. 67-95, doi: 10.1108/IJSMS-03-01-2001-B006.

Glantz, M. (2010), "The Floyd Landis doping scandal: implications for image repair discourse", Public Relations Review, Vol. 36 No. 2, pp. 157-163, doi: 10.1016/j.pubrev.2009.09.002.

Guthrie, J., Ricceri, F. and Dumay, J. (2012), "Reflections and projections: a decade of intellectual capital accounting research", The British Accounting Review, Vol. 44 No. 2, pp. 68-82, doi: 10. 1016/j.bar.2012.03.004.

Hammerschmidt, J., Durst, S., Kraus, S. and Puumalainen, K. (2021), "Professional football clubs and empirical evidence from the COVID-19 crisis: time for sport entrepreneurship?", Technological Forecasting and Social Change, Vol. 165, pp. 1-10, doi: 10.1016/j.techfore.2021.120572.

Hancock, D.J., Ste-Marie, D.M. and Schinke, R.J. (2010), “The development and skills of expert major junior hockey player agents", Talent Development and Excellence, Vol. 2 No. 1, pp. 51-62.

Hansen, P.Ø. (2015), "Managing core processes in elite athlete development: Norwegian cross-country skiing", in Andersen, S.S., Houlihan, B. and Ronglan, L.T. (Eds), Managing Elite Sport Systems. Research and Practice, Routledge, London and New York, pp. 89-106. 
$\mathrm{JIC}$ 23,7

Hoffmann, A. and Wulff, J. (2015), "Talent identification and development in Germany: state of play and current tasks", in Andersen, S.S., Houlihan, B. and Ronglan, L.T. (Eds), Managing Elite Sport Systems. Research and Practice, Routledge, London and New York, pp. 107-125.

Hormiga, E., Batista-Canino, R.M. and Sánchez-Medina, A. (2011), "The role of intellectual capital in the success of new ventures", International Entrepreneurship and Management Journal, Vol. 7 No. 1, pp. 71-92, doi: 10.1007/s11365-010-0139-y.

Inkinen, H., Kianto, A., Vanhala, M. and Ritala, P. (2017), "Structure of intellectual capital - an international comparison", Accounting, Auditing and Accountability Journal, Vol. 30 No. 5, pp. 1160-1183, doi: 10.1108/AAAJ-11-2015-2291.

Lardo, A., Dumay, J., Trequattrini, R. and Russo, G. (2017), "Social media networks as drivers for intellectual capital disclosure. Evidence from professional football clubs", Journal of Intellectual Capital, Vol. 18 No. 1, pp. 63-80, doi: 10.1108/JIC-09-2016-0093.

Leitão, J. and Baptista, J. (2019), "Intellectual capital assets and brand value of English football clubs", International Journal of Sport Management and Marketing, Vol. 19 Nos 1/2, pp. 8-34, doi: 10. 1504/IJSMM.2019.097002.

Lou, C. and Yuan, S. (2019), "Influencer marketing: how message value and credibility affect consumer trust of branded content on social media", Journal of Interactive Advertising, Vol. 19 No. 1, pp. 58-73, doi: 10.1080/15252019.2018.1533501.

Martin, B.C., McNally, J.J. and Kay, M.J. (2013), "Examining the formation of human capital in entrepreneurship: a meta-analysis of entrepreneurship education outcomes", Journal of Business Venturing, Vol. 28 No. 2, pp. 211-224, doi: 10.1016/j.jbusvent.2012.03.002.

Martin, L.A., Fogarty, G.J. and Albion, M.J. (2014), "Changes in athletic identity and life satisfaction of elite athletes as a function of retirement status", Journal of Applied Sport Psychology, Vol. 26 No. 1, pp. 96-110, doi: 10.1080/10413200.2013.798371.

Matthews, P. (2003), "Athletics 2003", The International Track and Field Annual, The Association of Track and Field Staticians, SportsBooks, Worcester \& Cheltenham.

Matthews, P. (2009), “Athletics 2009”, The International Track and Field Annual, The Association of Track and Field Staticians, SportsBooks, Worcester \& Cheltenham.

Mouritsen, J., Larsen, H.T. and Bukh, P.N. (2001), "Valuing the future: intellectual capital supplements at Skandia”, Accounting, Auditing \& Accountability Journal, Vol. 14 No. 4, pp. 399-422, doi: 10. 1108/09513570110403434.

Na, S., Kunkel, T. and Doyle, J. (2020), "Exploring athlete brand image development on social media: the role of signalling through source credibility", European Sport Management Quarterly, Vol. 20 No. 1, pp. 88-108, doi: 10.1080/16184742.2019.1662465.

Ohanian, R. (1991), “The impact of celebrity spokespersons' perceived image in consumers' intention to purchase", Journal of Advertising Research, Vol. 31 No. 1, pp. 46-54.

Parris, D.L., Troilo, M.L., Bouchet, A. and Peachey, J.W. (2014), "Action sports athletes as entrepreneurs: female professional wakeboarders, sponsorship, and branding”, Sport Management Review, Vol. 17 No. 4, pp. 530-545, doi: 10.1016/j.smr.2013.12.005.

Pedro, E., Leitão, J. and Alves, H. (2018), "Intellectual capital and performance: taxonomy of components and multi-dimensional analysis axes”, Journal of Intellectual Capital, Vol. 19 No. 2, pp. 407-452, doi: 10.1108/JC-11-2016-0118.

Pöppel, K., Dreiskämper, D. and Strauss, B. (2021), "Breaking bad: how crisis communication, dissemination channel and prevalence influence the public perception of doping cases", Sport in Society, Vol. 24 No. 7, pp. 1156-1182, doi: 10.1080/17430437.2020.1734563.

Puspitasari, K., Budisusetyo, S. and Zakiah, Z. (2019), "An accounting review of athletes in ownership of basketball club assets”, The Indonesian Accounting Review, Vol. 9 No. 2, pp. 169-180, doi: 10. 14414/tiar.v9i2.1770. 
Ratten, V. (2015), "Athletes as entrepreneurs: the role of social capital and leadership ability", International Journal of Entrepreneurship and Small Business, Vol. 25 No. 4, pp. 442-455, doi: 10. 1504/IJESB.2015.070217.

Richelieu, A. and Pons, F. (2006), "Toronto Maple Leafs vs. Football Club Barcelona: how two legendary sports teams built their brand equity", International Journal of Sports Marketing and Sponsorship, Vol. 7 No. 3, pp. 231-250, doi: 10.1108/IJSMS-07-03-2006-B009.

Saint-Onge, H. (1996), "Tacit knowledge the key to the strategic alignment of intellectual capital", Planning Review, Vol. 24 No. 2, pp. 10-16, doi: 10.1108/eb054547.

Sanderson, A.R. and Siegfried, J. (2015), "The case for paying college athlete", Journal of Economic Perspectives, Vol. 29 No. 1, pp. 115-138, doi: 10.1257/jep.29.1.115.

Sato, S., Ko, Y.J., Chang, Y. and Kay, M. (2019), "How does the negative impact of an athlete's reputational crisis spill over to endorsed and competing brands? The moderating effects of consumer knowledge", Communication and Sport, Vol. 7 No. 3, pp. 385-409, doi: 10.1177/2167479518783461.

Schultz, T.W.(1961), "Investment in human capital", The American Economic Review, Vol. 51 No. 1, pp. 1-17.

Seno, D. and Lukas, B.A. (2007), "The equity effect of product endorsement by celebrities. A conceptual framework from a co-branding perspective", European Journal of Marketing, Vol. 41 Nos 1/2, pp. 121-134, doi: 10.1108/03090560710718148.

Stambulova, N., Alfermann, D., Statler, T. and Côté, J. (2011), "ISSP Position stand: career development and transitions of athletes", International Journal of Sport and Exercise Psychology, Vol. 7 No. 4, pp. 395-412, doi: 10.1080/1612197X.2009.9671916.

$\mathrm{Su}$, Y., Baker, B.J., Doyle, J.P. and Kunkel, T. (2020), "The rise of an athlete brand: factors influencing the social media following of athletes", Sport Marketing Quarterly, Vol. 29 No. 1, pp. 33-46, doi: 10.32731/SMQ.291.302020.03.

Szymanski, S. (2003), "The assessment: the economics of sport", Oxford Review of Economic Policy, Vol. 19 No. 4, pp. 467-477.

Vitolla, F., Raimo, N., Rubino, M. and Garzoni, A. (2021), "Broadening the horizons of intellectual capital disclosure to the sports industry: evidence from top UEFA clubs", Meditari Accountancy Research, Vol. 30 No. 1, pp. 142-162, doi: 10.1108/MEDAR-08-2020-0973.

Warkentin, M., Scuotto, V. and Edvinsson, L. (2021), "Guest editorial "Twenty years of history: the 20th anniversary special issue of Journal of Intellectual Capital”, Journal of Intellectual Capital, Vol. 22 No. 3, pp. 433-438, doi: 10.1108/JIC-05-2021-389.

West, P. (2016), The United States of Soccer, Harry N. Abrams, New York.

Wicker, P., Hallmann, K., Breuer, C. and Feiler, S. (2012), "The value of Olympic success and the intangible effects of sport events - a contingent valuation approach in Germany", European Sport Management Quarterly, Vol. 12 No. 4, pp. 337-355, doi: 10.1080/16184742.2012.693117.

Woolcock, M. and Narayan, D. (2000), "Social capital: implications for development theory, research, and policy”, The World Bank Research Observer, Vol. 15 No. 2, pp. 225-249, doi: 10.1093/wbro/15.2.225.

Yusoff, W.F.W., Jantan, M. and Ibrahim, D.N. (2004), "The interactive effects of human capital, structural capital and social capital on firm performance", Asian Academy of Management Journal, Vol. 9 No. 2, pp. 1-18.

\section{Corresponding author}

Roberto Aprile can be contacted at: roberto.aprile@unibg.it 